\title{
The effect of mineral fertilization on nutritive value and biological activity of chokeberry fruit
}

\author{
Katarzyna Skupień \\ Laboratory of Plant Raw Materials Processing and Storage, \\ Agricultural University of Szczecin, ul. Stowackiego 17, 71-434 Szczecin, Poland, \\ e-mail:kskupien@agro.ar.szczecin.pl \\ Jan Oszmiański \\ Department of Fruit, Vegetables and Cereal Technology, Agricultural University of Wroctaw, Poland, \\ e-mail:oszm@ozi.ar.wroc.pl
}

\begin{abstract}
The aim of the study was to assess whether an extra fertilization with manganese, commercial fertilizer Alkalin ( $\mathrm{N}, \mathrm{K}$ and $\mathrm{Si}$ ), and combined treatment (manganese + Alkalin) affect the chemical composition of chokeberry fruits (Aronia melanocarpa (Michx) Elliot), especially sugar content and the quantity and profile of phenolics. Dry weight, soluble solids, titratable acidity, total sugar, reducing sugar, sucrose, vitamin C, total polyphenol (gallic acid equivalents); 2, 2-diphenyl-1-picrylhydrazyl radical scavenging activity; and phenolics profile were measured from the fruits harvested from different treatments. Chokeberries treated with manganese showed high content of non-identified phenolic acids [101.15 mg per $100 \mathrm{~g}$ fresh weight (FW), these compounds were not detected in fruit treated with Alkalin and manganese + Alkalin], and the highest content of cyanidin glycosides $(813.75 \mathrm{mg}$ per $100 \mathrm{~g} \mathrm{FW})$. The fruits treated with Alkalin displayed the highest content of quercetin derivatives ( $40.88 \mathrm{mg}$ per $100 \mathrm{~g} \mathrm{FW}$ ) and eriodictyol 7 -glucuronide (26.43 $\mathrm{mg}$ per $100 \mathrm{~g} \mathrm{FW})$. Chokeberries in control treatments had the highest content of dry weight $(30.76 \% \mathrm{FW})$,


(2377.1 mg gallic acid equivalents per $100 \mathrm{~g} \mathrm{FW}$ ), the highest 2, 2-diphenyl-1-picrylhydrazyl radical \% inhibition (38.1\%), highest content of chlorogenic acids (210.38 mg per $100 \mathrm{~g} \mathrm{FW})$, (-)epicatechin (32.18 mg per $100 \mathrm{~g} \mathrm{FW}$ ) and the highest degree of procyanidin polimerization (59). The results indicate that applied fertilization exerted differential influence on chemical composition of aronia fruits.
\end{abstract}

Key-words: chokeberry, fertilizers, fruit chemical composition, Aronia melanocarpa

\section{Introduction}

Black chokeberry (Aronia melanocarpa (Michx) Elliot) belongs to the Rosaceae family and is native to eastern North America (Jeppsson 2000). In
Poland aronia shrubs meant for fruit production were introduced in the 1970s. Chokeberries are rich in phenolic compounds and have been reported to have antioxidative effects in vitro and in vivo. Ogha- 


\section{AGRICULTURAL AND FOOD SCIENCE}

Vol. 16 (2007): 46-55

mi et al. (2005) noted an anti-inflamatory effect of aronia crude extract on endotoxin-induced uveitis in rats. Valcheva-Kuzmanova et al. (2004) studied the influence of the natural aronia juice on carbon tetrachloride $\left(\mathrm{CCl}_{4}\right)$-induced acute liver damage in rats. Chokeberry juice in a dose-dependent manner reduced necrotic changes in rat livers and inhibited the increase of plasma aspartate transaminase and alanine transaminase activities, induced by $\mathrm{CCl}_{4}$. In 2005, Valcheva-Kuzmanova et al. investigated the effect of aronia juice pretreatment on indomethacin-induced gastric mucosal damage. The authors found that the administration of chokeberry juice diminished the number, area and severity of indomethacin-induced mucosal lesions. Similarly, Matsumoto et al. (2004) observed that aronia extract and its hydrolysate had a protective effect in suppressing the area of gastric mucosal damage caused by the subsequent application of ethanol to $<30 \%$ in treated rats compared to the control group. Jankowski et al. (2000) noticed that administration of aronia pigments to rats before intraperitoneal injections of Platelet Activating Factor and ceruleine had a suppressive effect on the development of acute experimental pancreatitis in animal study. Other phenolics of aronia (catechins, quercetin etc.) manifest anti-bacterial, anti-fungal, anti-viral and anti-mutagenic activity. Chokeberry anthocyanins exert protective effects towards UV radiation, thus they are of interest in cosmetic production.

The phenolic content of plants depends, both quantitatively and qualitatively, on genetic information (species, variety per cultivar). The environment also plays an important role in determining the phenolic profile of fruits and vegetables. Extrinsic factors such as geographical conditions (Schaffer et al. 2005), climate, season, light, temperature, and degree of ripeness strongly influence phenolic synthesis in plants (Aherne and O'Brian 2002). There are opposite observations referring to cultivation techniques applied. Carbonaro et al. (2002) noticed an improvement in the antioxidant defence system of the plant (peach and pear) as a possible consequence of the agronomic cultivation practices; whereas, Häkkinen and Törrönen (2000) found similar contents of phenolics in three strawberry cultivars grown by conventional and organic farming.

Among all common fruits in the diet, berries (especially those with dark blue or red colors) have the highest antioxidant capacities (Wu et al. 2004a). In recent years, the potential of aronia fruits has been recognized as a source of food colorants and valuable phytonutrients (Slimestad et al. 2005). Chokeberries have specific astringent taste, and thus are not favoured as table fruits. Mineral fertilization, among other agronomic practices, may influence the nutritive value and the content of biologically active compounds of the fruits. Cultivation methods can be used to enhance the content of phenolics and pigmentation of fruits, although the information on this topic is very scarce and often contradictory (Tomás-Barberán and Espin 2001).

Severe Mn deficiency affects the stability of the chloroplast lamellar systems thus reducing photosynthesis and carbohydrate production in leaves (Pearson and Rengel 1997). Manganese is available to the plant in acidic and waterlogged soils (Shi et al. 2005); deficiency of Mn occurs in neutral and alkaline reaction soils. The most rapid and efficient way to prevent and/or correct Mn deficiency is foliar application of solutions containing inorganic or organic Mn (Papadakis et al. 2005). Silicon (Si) is involved in enhancing disease resistance of plants. Moreover Si was found to alleviate Mn toxicity in cucumber plants treated with an excess of $\mathrm{Mn}$ (Shi et al. 2005). Potassium (K) fertilization has been widely used in agronomic practice to increase sucrose content in sugar beets and starch content in potatoes and grains. Chapagain and Wiesman (2004) noticed higher glucose content in tomato fruits treated with monopotassium phosphate compared to control. Astringent, bitter, and sour tastes of chokeberries result from high content of chlorogenic acids and procyanidins. Awad and de Jager (2002) found negative correlation between $\mathrm{N}$ (nitrogen), $\mathrm{K}$ and chlorogenic acid concentration in the skin of 'Elshof' apples. In recent literature, data referring to influence of mineral fertilization on chemical composition of aronia fruits, especially phenolics, is scarce (Jeppsson 2000).

In this study, we estimated whether manganese (Mn), Alkalin (N, K and Si), and combined fertiliza- 


\section{AGRICULTURAL AND FOOD SCIENCE}

Skupień, K. \& Oszmiański, J. Mineral fertilization of chokeberry fruit

tion (Mn + Alkalin) influence the content of basic nutritive compounds and improve sensory attributes (increase sugar content), and thereby the nutritive value of chokeberries. Moreover, we investigated whether applied fertilization may affect the synthesis of phenolic compounds (imparting astringency) and influence antioxidant activity of aronia fruit.

\section{Material and methods}

\section{Experimental}

Chokeberry fruits were obtained from the Experimental Station at Rajkowo near Szczecin, northwest Poland. The plantation was established on grey brown podsolic soil originated from medium boulder clay. Rooted cuttings of aronia were planted in 1995. In October 2003, shrub amelioration was performed by rejuvenate cutting and only 5 shoots were left per plant. The experiment was carried out in 2005. Two doses of nitrogen, $40 \mathrm{~kg} \mathrm{~N} \mathrm{ha}^{-1}$ each, were used for basic fertilization. Phosphorus and potassium fertilizations were not applied because the soil was abundant in these elements $(7.3 \mathrm{mg}$ per $100 \mathrm{~g}$ and $48.0 \mathrm{mg}$ per $100 \mathrm{~g}$, respectively) and followed the recommendations for fruit orchards on clay soils. Soil reaction was neutral $(\mathrm{pH}=$ 7.1). Additionally, three different fertilizers were applied by foliar spray: chelate manganese [(Mn ethylene-diamine-tetraacetic acid (EDTA), diethylene-triamine-pentaacetate (DTPA)] in a dose of $1 \mathrm{~g} \mathrm{l}^{-1}$, Alkalin fertilizer ( $\mathrm{N}, \mathrm{K}$ and $\mathrm{Si}$ ) in a dose of $5 \mathrm{ml} \mathrm{l}^{-1}$, and $\mathrm{Mn}+$ Alkalin (combined dose). Manganese fertilizer contained $14 \mathrm{~g}$ of manganese per

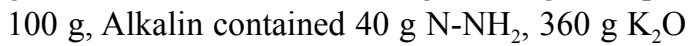
and $15 \mathrm{~g} \mathrm{SiO}_{2} 1^{-1}$. Adjuvat Superam $10 \mathrm{AL}(10 \%$ salt of alkylbenzensulfonic acid and etoxyalkylphenols) was added by spraying, using a dose of 50 $\mathrm{ml}$ per 1001 . The fertilizers were purchased from Intermag, Poland. The sprays were performed six times on 18, 24 and 31 May and 7, 16 and 30 June 2005. Every treatment comprised of five bushes in three replicates. Control plants were sprayed with Superam 10 AL diluted in distilled water; whereas, the basic nitrogen fertilization was applied in the same dose and term as for fertilizer treatments. From florescence to harvest, drip irrigation in a cycle of 3 hs per day was used when the length of drought lasted for more than seven days. Total water consumption was 10001 per plantation. Weed control was performed chemically between rows [Kerb (Dow AgroSciences Poland) + Azotop before vegetative season] and using Roundup within rows (before flowering). Because Aronia melanocarpa plants are resistant to pathogen diseases, no chemical protection was needed. The fruits - one-kg bulk samples - were collected in full-ripeness stage on 7 September.

\section{Plant material}

Dry weight, soluble solids, titratable acidity, total sugar, reducing sugar, vitamin $\mathrm{C}$, total polyphenol content, and measurements for 2, 2-diphenyl-1picrylhydrazyl radical (DPPH') \% inhibition were performed on fresh fruits packed in polyethylene bags and stored overnight at $5^{\circ} \mathrm{C}$. Phenolic composition was determined by high-performance liquid chromatography (HPLC) on fruits packed as above and stored for 5 days at $5^{\circ} \mathrm{C}$.

\section{Chemicals}

All the chemicals used for analyses were of analytical grade and purchased from POCh (Gliwice, Poland). High performance liquid chromatography chemicals were of HPLC purity and purchased from Sigma-Aldrich (USA).

\section{Analyses}

Dry weight of fruit was determined with a gravimetric method (an aliquot $\sim 5 \mathrm{~g}$ of fruit tissue was dried at $105^{\circ} \mathrm{C}$ to constant weight) according to Polish standard (PN-90/A-75101/03).

Soluble solids content was determined with an Abbé refractometer (PN-90/A-75101/02).

Titratable acidity was determined by titration of a water extract of chokeberry homogenate with 
$0.1 \mathrm{~N} \mathrm{NaOH}$ to the end point of $\mathrm{pH} 8.1$ (measured with an Orion $720 \mathrm{~A} \mathrm{pH}$ meter; Orion Research Incorporated, Boston, MA, USA) according to PN-90/A-75101/04.

Total sugar and reducing sugar content were determined according to the Loof-Schoorl method. Sucrose content was calculated according to the relationship: sucrose $=$ (total sugar - reducing sugar) $\times 0.95$.

Vitamin $\mathrm{C}$ was determined as L-ascorbic acid using the Tillmans method (titration of an $10 \mathrm{ml}$ aliquot of oxalic acid berry extract by means of 0.025\% 2,6-dichlorophenol-indophenol according to PN-90/A-75101/1) prior to adsorption of pigments into $\mathrm{C}_{18}$ Sep-Pak cartridge (Waters Associates, Milford, MA, USA) from an acid extract of chokeberry homogenate.

Total polyphenol content in the methanol (70\%) extracts was estimated according to Singleton and Rossi (1965) with the Folin-Ciocalteu reagent. The data is expressed as mg of gallic acid equivalents (GAE) per $100 \mathrm{~g}$ of fruit tissue.

\section{DPPH-radical percent inhibition}

The DPPH was obtained from Sigma-Aldrich Co. (USA). Scavenging effect of chokeberry fruit on DPPH-radical was determined according to the method of Yen and Chen (1995) with some modification. The fruits were homogenised with a food processor (Predom Zelmer, Poland) and the juice was squeezed through cheese cloth. Further, the raw juice was centrifuged at $8,000 \times \mathrm{g}$ (centrifuge MPW-250, MPW Med. Instruments, Poland) and diluted 400 times in methanol $\left(32.04 \mathrm{~g} \mathrm{~mol}^{-1}\right)$. A $1 \mathrm{ml}$ aliquot of diluted juice was added to $3 \mathrm{ml}$ of methanol and $1 \mathrm{ml}$ of DPPH solution $(0.012 \mathrm{~g}$ DPPH per $100 \mathrm{ml}$ ). The mixture was shaken and left at room temperature for $10 \mathrm{~min}$; the absorbance was measured spectrophotometrically at $517 \mathrm{~nm}$. DPPH percent inhibition was calculated according to Rossi et al. (2003) from the formula: Percent inhibition $=100-\left[\left(A_{t} / A_{r}\right) \times 100\right]$, where $A_{t}-a b-$ sorbance of test solution and $A_{r}$ - absorbance of reference solution.

\section{HPLC analyses}

Cooled berries were homogenized with DIAX 900 (Heidolph, Germany) homogenizer. Aliquots of $1 \mathrm{~g}$ of fruit tissue were extracted with methanol acidified with $0.1 \% \mathrm{HCl}$. The extraction was performed in an ultrasonic bath for $20 \mathrm{~min}$. This has proved to be adequate for complete extraction. The slurry was centrifuged at $19000 \times \mathrm{g}$ for $10 \mathrm{~min}$ and the supernatant was used for HPLC analysis. The supernatant was recovered and filtered through a 0.45 $\mu \mathrm{m}$ cellulose syringe filter before analysis.

The HPLC analyses of (-)epicatechin, hydroxycinnamates, anthocyanin glycosides and flavonol glycosides were carried out on a HPLC apparatus consisting of a Merck-Hitachi L-7455 diode array detector (DAD) and quaternary pump L-7100 equipped with D-7000 HSM Multisolvent Delivery System (Merck-Hitachi, Tokyo, Japan). The separation was performed on a Synergi Fusion RP-80A $150 \times 4.6 \mathrm{~mm}(4 \mu \mathrm{m})$ Phenomenex (Torrance, CA USA) column. Column oven temperature was set at $30^{\circ} \mathrm{C}$. The mobile phase was composed of solvent A (2.5\% acetic acid, pH 2.9) and solvent B (acetonitrile). The program began with a linear gradient from $0 \% \mathrm{~B}$ to $25 \% \mathrm{~B}(0-36 \mathrm{~min})$, followed by washing and reconditioning the column. The flow rate was $1 \mathrm{ml} \cdot \mathrm{min}^{-1}$ and the runs were monitored at the following wavelengths: (-)epicatechin at $280 \mathrm{~nm}$, chlorogenic and neochlorogenic acid at $320 \mathrm{~nm}$, flavonol glycosides at $360 \mathrm{~nm}$, and anthocyanin glycosides at $520 \mathrm{~nm}$. The Photo Diode Array spectra were measured over the wavelength range $240-600 \mathrm{~nm}$ in steps of $2 \mathrm{~nm}$. Retention times and spectra were compared to those of pure standards within 200-600 nm. Standards of cyanidin 3 -galactoside and chlorogenic acid were obtained from Polyphenols Laboratories (Norway) while rutin from Sigma-Aldrich and chlorogenic acid from Extrasynthese (France). Eriodictyol-7-glucuronide was identified according to the literature data (Justesen et al. 1998). 


\section{Proanthocyanidin analysis}

The direct thiolysis on freeze-dried berries was performed. Powders were precisely weighed (30-50 $\mathrm{mg})$ in $1.5 \mathrm{ml}$ Eppendorf vials, acidified methanol $(3.3 \% \mathrm{v} / \mathrm{v}, 400 \mu \mathrm{l})$ and toluene alpha-thiol $(5 \%$ in methanol, $800 \mu \mathrm{l})$ were added. The vials were closed and incubated at $40^{\circ} \mathrm{C}$ for $30 \mathrm{~min}$ with agitation on vortex every $10 \mathrm{~min}$. Then, the vials were cooled in ice water and centrifuged immediately at $4^{\circ} \mathrm{C}$ in a refrigerated centrifuge for $10 \mathrm{~min}$. Samples were stored at $4^{\circ} \mathrm{C}$ until RP-HPLC analysis. Each sample was performed in triplicate.

The thiolysis products were separated on Merck Purospher RP 18 end-capped column $250 \times 4 \mathrm{~mm}$, $5 \mu \mathrm{m}$ (Merck, Darmstadt, Germany). The HPLC apparatus employed was a Waters (Milford, MA, USA) system (DAD and Scanning Fluorescence detectors). The solvent system was composed of solvent A (aqueous acetic acid, 2.5\% v/v) and solvent B (acetonitrile). The following gradient was applied: initially 3\% B; 0-5 min 9\% B linear; 5-15 min 16\% B linear; and 15-45 min 50\% B linear, followed by washing and reconditioning the column. The flow rate was $1 \mathrm{ml} \cdot \mathrm{min}^{-1}$ and oven temperature was $30^{\circ} \mathrm{C}$. Compounds for which reference standards were available were identified on chromatograms according to their retention times and UV-visible spectra. The fluorescence detection was recorded at excitation wavelength 278 and emission wavelength $360 \mathrm{~nm}$. The calibration curves (based on peak area at $280 \mathrm{~nm}$ ) were established using flavan-3-ol and benzylthioether standards. The average degree of polymerization was measured by calculating the molar ratio of all the flavan-3-ol units (thioether adducts + terminal units) to (-)epicatechin and (+)catechin corresponding to terminal units.

\section{Statistical analysis}

Statistical analysis was done by using Statistica software package version 7.1 (Statsoft, Poland). The data were subjected to one-way analysis of variance. Values of $\mathrm{P}<0.05$ (Tukey multiple comparison test) were considered significant.

\section{Results and discussion}

Data presenting the basic chemical composition of treated and untreated chokeberry fruits is listed in Table 1.

Chokeberry fruits in control treatment (basic nitrogen + Superam) showed significantly higher dry weight content compared to berries of Mn treatment (by $13 \%$ ), higher by $9 \%$ than that of $\mathrm{Mn}+$ Alkalin treatment, and by $6 \%$ compared to that of Alkalin treatment. The dry weight content obtained in our experiment (30.76-26.67\%) exceeds the values reported by Kleparski and Domino (1990). In their experiments, dry weight content varying from $17 \%$ to $26 \%$ was observed. Berries of control treatment showed also the highest soluble solids content, surpassing treated variants by $10 \%(\mathrm{Mn}), 9 \%(\mathrm{Mn}$ + Alkalin) and 5\% (Alkalin). However, the differences were not statistically significant. Soluble solids content ranged from $21.7^{\circ} \mathrm{Bx}(\mathrm{Mn})$ to $24.1{ }^{\circ} \mathrm{Bx}$ (control). The values were much higher compared to that determined by Jeppsson (2000) 16.3-17.8 ${ }^{0} \mathrm{Bx}$. In our experiment, favourable weather conditions occurred during fruit ripening (warm, sunny August and September) and this could stimulate synthesis of different compounds (mainly sugars) which yield soluble solids content. The weather factor may have considerably contributed to the differences observed between the two studies.

On the other hand, all the fertilizer treatments applied in this experiment caused the increase of total acid content in the fruits. Berries obtained from Alkalin and manganese treatments showed significantly higher titratable acidity than control ones (by $11 \%$ and $9 \%$, respectively) whereas the fruit of combined $\mathrm{Mn}+$ Alkalin fertilization exhibited total acidity higher by $5 \%$, in comparison to control chokeberries. Jeppsson (2000) noted that increased rates of $\mathrm{N}, \mathrm{P}$, and $\mathrm{K}$ fertilization reduced total acidity in chokeberries. In our experiment, Alkalin $(\mathrm{N}$, $\mathrm{K}$, and $\mathrm{Si}), \mathrm{Mn}$, and combined fertilization $(\mathrm{Mn}+$ Alkalin) exerted opposite effect.

Total sugar content estimated in aronia berries was high (19.32-20.92 g per $100 \mathrm{~g}$ ), compared to $6.2-10.8 \mathrm{~g}$ per $100 \mathrm{~g}$ reported by Kleparski and Domino (1990). Alkalin fertilization is recom- 


\section{AGRICULTURAL AND FOOD SCIENCE}

Vol. 16 (2007): 46-55

Table 1. Chemical composition and 2, 2-diphenyl-1-picrylhydrazyl radical (DPPH') \% inhibition of chokeberry fruit in different fertilization treatments.

\begin{tabular}{|c|c|c|c|c|}
\hline Characteristics $^{\text {a }}$ & Control & Manganese & Alkalin & Manganese + Alkalin \\
\hline Dry weight (\%) & $30.76^{\mathrm{a}}$ & $26.67^{b}$ & $28.76^{\mathrm{ab}}$ & $28.06^{\mathrm{ab}}$ \\
\hline Soluble solids $\left({ }^{0} \mathrm{Bx}\right)$ & $24.1^{\mathrm{a}}$ & $21.7^{\mathrm{a}}$ & $23.0^{\mathrm{a}}$ & $21.9^{\mathrm{a}}$ \\
\hline $\begin{array}{l}\text { Titratable acidity } \\
\text { (g citric acid per } 100 \mathrm{~g} \text { ) }\end{array}$ & $0.493^{\mathrm{b}}$ & $0.535^{\mathrm{a}}$ & $0.548^{\mathrm{a}}$ & $0.519^{\mathrm{ab}}$ \\
\hline Total sugar (g per $100 \mathrm{~g}$ ) & $20.92^{\mathrm{a}}$ & $19.36^{\mathrm{b}}$ & $19.32^{\mathrm{b}}$ & $19.82^{\mathrm{b}}$ \\
\hline Reducing sugar (g per $100 \mathrm{~g}$ ) & $19.35^{\mathrm{a}}$ & $19.36^{\mathrm{a}}$ & $19.27^{\mathrm{a}}$ & $18.21^{\mathrm{b}}$ \\
\hline Saccharose (g per $100 \mathrm{~g}$ ) & $1.50^{\mathrm{a}}$ & $0.00^{\mathrm{b}}$ & $0.05^{\mathrm{b}}$ & $1.53^{\mathrm{a}}$ \\
\hline Vitamin C (mg per $100 \mathrm{~g})$ & $8.4^{\mathrm{a}}$ & $1.9^{\mathrm{b}}$ & $3.4^{\mathrm{b}}$ & $3.9^{\mathrm{b}}$ \\
\hline $\begin{array}{l}\text { Total polyphenol } \\
\text { (mg gallic acid per } 100 \mathrm{~g} \text { ) }\end{array}$ & $2377.1^{\mathrm{a}}$ & $2181.9^{b}$ & $2165.2^{b}$ & $2105.0^{\mathrm{b}}$ \\
\hline $\mathrm{DPPH}^{*} \%$ inhibition $^{\mathrm{b}}$ & $38.1^{\mathrm{a}}$ & $31.6^{\mathrm{a}}$ & $29.8^{\mathrm{a}}$ & $31.6^{\mathrm{a}}$ \\
\hline
\end{tabular}

${ }^{a}$ Values are the mean of three determinations and are expressed per fresh weight. Different letters in the same row indicate significant differences at $\mathrm{P}<0.05$.

${ }^{\mathrm{b}}$ DPPH-radical \% inhibition was calculated on the basis of $\mathrm{DPPH}^{*}$ scavenging activity of chokeberry juice diluted 400 times in reaction mixture consisting of: $1 \mathrm{ml}$ of diluted juice $+3 \mathrm{ml}$ of absolute methanol $+1 \mathrm{ml} \mathrm{of} \mathrm{DPPH}^{*}$ solution.

mended to increase sugar content in the yield (effect of K). Similarly, Mn activates many enzymes involved in sugar synthesis. Mn shortage results in drastic sugar content decline (Starck 2002). In contrast to our expectations, significantly higher total sugar content was found in control fruits. Fruits obtained from Alkalin treatment displayed a decrease of total sugar by $1.60 \mathrm{~g}$ per $100 \mathrm{~g}$, and berries from $\mathrm{Mn}+$ Alkalin treatment by $1.10 \mathrm{~g}$ per $100 \mathrm{~g}$ compared to control ones. Further, combined treatment $(\mathrm{Mn}+$ Alkalin) caused significant lowering of reducing sugar content (by $>1 \mathrm{~g}$ per $100 \mathrm{~g}$ ) compared to other treatments. All these changes were reflected in sucrose content. Similar level of sucrose was observed in control berries and that of combined treatment $(\mathrm{Mn}+$ Alkalin $) \sim 1.5 \mathrm{~g}$ per 100 $\mathrm{g}$, while no sucrose was measured in manganese fertilizer treatment and only negligible in Alkalin treatment.

Chokeberry fruits do not contain considerable amounts of vitamin C. According to Kalemba et al. (1995), vitamin $C$ content in aronia ranges from 14 to $28 \mathrm{mg}$ per $100 \mathrm{~g}$ fresh weight. The content of ascorbic acid found in the study was very low $1.9-8.4 \mathrm{mg}$ per $100 \mathrm{~g}$. The most distinct differences were determined between control fruits and berries of fertilizer treatments. Control berries showed significantly more ascorbic acid ( $~ 4$-times) than fruit of Mn treatment, and 2.5 and 2.2-times more ascorbic acid than berries of Alkalin and combined treatment $(\mathrm{Mn}+$ Alkalin), respectively.

Total polyphenol content in chokeberries presented in the literature on dry weight basis varied from $40.1 \mathrm{mg}$ GAE per $\mathrm{g}-4210 \mathrm{mg}$ GAE per 100 g (Kähkönen et al. 1999, 2001, respectively) to $7849.21 \mathrm{mg}$ per $100 \mathrm{~g}$ (lyophilized berries) (Oszmiański and Wojdylo 2005). Benvenuti et al. (2004) reported total polyphenol content for fresh aronia fruit $690.2 \mathrm{mg}$ per $100 \mathrm{~g}$. In this study, in all tested treatments, total polyphenol content was $>2000 \mathrm{mg}$ per $100 \mathrm{~g}$ (according to GAE and HPLC). Environmental and agronomic conditions and date of harvest may have contributed to the differences observed between the two studies. Control chokeberries displayed significantly higher amount of total polyphenol (2377.1 mg GAE per $100 \mathrm{~g}$ per fresh weight) compared to the fruit of fertilizer treatments. Chokeberries of Mn treatment had by $195 \mathrm{mg}$ per $100 \mathrm{~g}$, berries of Alkalin treatment by $212 \mathrm{mg}$ per $100 \mathrm{~g}$ and fruit of $\mathrm{Mn}+$ Alkalin treatment by $272 \mathrm{mg}$ per $100 \mathrm{~g}$ less phenolics than control ones. High content of polyphenols is 
associated with high activity of L-phenylalanine ammonia-lyase (PAL), a key enzyme in the biosynthesis of phenolic compounds in fruit tissues of several species (Cheng and Breen 1991). Carver et al. (1998) reported a higher increase in PAL activity in Si-deprived plants. The authors suggested that this rise in PAL activity is to compensate the lack of $\mathrm{Si}$, and this compensation contributed to pathogen resistance in Si-deficient oat leaves.

\section{DPPH $\%$ inhibition}

Antioxidant properties of aronia fruits are evidenced in the literature. Nakajima et al. (2004) estimated DPPH-radical scavenging activity of aronia extract nearly identical to bilberry extract, though weaker than that of Trolox. Oszmiański and Wojdylo (2005) determined $\mathrm{DPPH}^{\circ}$ quenching activity for aronia lyophilized fruits $279.38 \mu \mathrm{M}$ Trolox per $100 \mathrm{~g}$ on dry weight basis. Matsumoto et al. (2004) showed that the chokeberry red pigment fraction scavenged $>44 \%$ of DPPH-radicals at a concentration $25 \mu \mathrm{g}$ $\mathrm{ml}^{-1}$ compared to the control solution. In this study, $\mathrm{DPPH}^{*} \%$ inhibition of aronia juice (diluted $1: 400$ ) ranged from 29.8 to $38.1 \%$, but the variants did not vary significantly. The highest $\mathrm{DPPH}^{*} \%$ inhibition was observeded for the control berries which showed the highest total polyphenol content (as GAE and HPLC). The results obtained by Yilmaz and Toledo (2004) indicated that polymeric procyanidins accounted for a most of the antioxidant activity of grape seeds. In our experiment, it was confirmed for the fruit from control group, which exhibited high procyanidin content with the highest degree of polymerization (Table 2). On the other hand, the same $\mathrm{DPPH}^{*} \%$ inhibition was found for the berries of $\mathrm{Mn}$ and $\mathrm{Mn}+$ Alkalin treatments $(31.6 \%)$, though chokeberries of combined treatment showed procyanidin content almost as high as control berries ( $1645.57 \mathrm{mg}$ per $100 \mathrm{~g}$ ), but with the lowest degree of polymerization (42), while berries of $\mathrm{Mn}$ treatment displayed the lowest procyanidin content (1426.66 mg per $100 \mathrm{~g}$ ), but with higher degree of polymerization (52) compared to fruit of combined treatment (Table 2).

Table 2. Phenolic compounds pattern of chokeberry fruits in different fertilization treatments.

\begin{tabular}{|c|c|c|c|c|}
\hline Items $^{\text {a }}$ & Control & Manganese & Alkalin & Manganese + Alkalin \\
\hline Chlorogenic acid & $110.62^{\mathrm{a}}$ & $83.97^{\mathrm{c}}$ & $94.34^{\mathrm{b}}$ & $91.50^{\mathrm{b}}$ \\
\hline Neochlorogenic acid & $99.76^{\mathrm{a}}$ & $79.09^{\mathrm{b}}$ & $82.42^{\mathrm{b}}$ & $74.60^{c}$ \\
\hline Nonidentified phenolic acid (r.t. 16.4 min) & $6.08^{\mathrm{b}}$ & $13.88^{\mathrm{a}}$ & $0.00^{\mathrm{c}}$ & $0.00^{\mathrm{c}}$ \\
\hline Nonidentified phenolic acid (r.t. 35.4 min) & $7.69^{\mathrm{b}}$ & $87.27^{\mathrm{a}}$ & $0.00^{\mathrm{c}}$ & $0.00^{\mathrm{c}}$ \\
\hline (-)epicatechin & $32.18^{\mathrm{a}}$ & $15.76^{\mathrm{c}}$ & $17.47^{\mathrm{b}}$ & $17.35^{\mathrm{b}}$ \\
\hline Polymeric procyanidins & $1645.64^{\mathrm{a}}$ & $1426.66^{\mathrm{b}}$ & $1616.50^{\mathrm{a}}$ & $1645.57^{\mathrm{a}}$ \\
\hline Degree of polymerization & $59^{\mathrm{a}}$ & $52^{\mathrm{b}}$ & $45^{\mathrm{c}}$ & $42^{\mathrm{d}}$ \\
\hline Quercetin 3-rutinoside $^{\mathrm{b}}$ & $6.14^{\mathrm{a}}$ & $5.50^{\mathrm{b}}$ & $6.27^{\mathrm{a}}$ & $6.02^{\mathrm{a}}$ \\
\hline Quercetin 3-galactoside & $13.18^{\mathrm{b}}$ & $9.91^{\mathrm{c}}$ & $14.57^{\mathrm{a}}$ & $13.08^{\mathrm{b}}$ \\
\hline Quercetin 3-glucoside & $8.06^{\mathrm{b}}$ & $7.07^{\mathrm{c}}$ & $8.87^{\mathrm{a}}$ & $7.83^{\mathrm{b}}$ \\
\hline Quercetin 3-vicianoside & $5.38^{\mathrm{a}}$ & $3.84^{\mathrm{c}}$ & $5.41^{\mathrm{a}}$ & $5.12^{\mathrm{b}}$ \\
\hline Quercetin 3-robinobioside & $5.42^{\mathrm{b}}$ & $5.66^{\mathrm{ab}}$ & $5.76^{\mathrm{a}}$ & $5.51^{\mathrm{ab}}$ \\
\hline Eriodictyol 7-glucouronide & $24.41^{\mathrm{ab}}$ & $22.11^{\mathrm{b}}$ & $26.43^{\mathrm{a}}$ & $23.46^{\mathrm{ab}}$ \\
\hline Cyanidin 3-galactoside & $515.22^{\mathrm{a}}$ & $512.93^{\mathrm{a}}$ & $477.77^{b}$ & $473.54^{b}$ \\
\hline Cyanidin 3-glucoside & $21.51^{\mathrm{a}}$ & $18.15^{\mathrm{c}}$ & $19.81^{\mathrm{b}}$ & $19.36^{\mathrm{b}}$ \\
\hline Cyanidin 3-arabinoside & $238.73^{b}$ & $249.46^{\mathrm{a}}$ & $223.44^{c}$ & $220.27^{\mathrm{c}}$ \\
\hline Cyanidin 3-xyloside & $33.39^{\mathrm{a}}$ & $33.21^{\mathrm{a}}$ & $30.27^{b}$ & $30.63^{\mathrm{b}}$ \\
\hline Total & $2773.41^{\mathrm{a}}$ & $2574.47^{b}$ & $2629.33^{b}$ & $2633.84^{\mathrm{b}}$ \\
\hline
\end{tabular}

${ }^{a}$ Values are the mean of three determinations and are expressed as $\mathrm{mg}$ per $100 \mathrm{~g}$ of fresh weight.

${ }^{\mathrm{b}}$ Rutin was used as an equivalent for quantifications. 
Vol. 16 (2007): 46-55

\section{Phenolic profile}

The results of the qualitative and quantitative composition of phenolic compounds in chokeberry fruits are presented in Table 2 and for control treatment in Figure 1. Chlorogenic acid and neochlorogenic acid were the two dominating phenolic acids identified in aronia fruits. Phenolic acids, among other phenolic compounds, impart the sour and bitter taste and astringent effect while consuming fruit. Oszmiański and Wojdylo (2005) found in lyophilized chokeberries 301.85 and $290.81 \mathrm{mg}$ per $100 \mathrm{~g}$ per dry weight chlorogenic and neochlorogenic acid, respectively. Slimestad et al. (2005) estimated in fresh aronia fruit higher amount of neochlorogenic acid (123 mg per 100 g) than chlorogenic acid (61 mg per $100 \mathrm{~g})$. In our study, chlorogenic acid amounts were higher than neochlorogenic acid. Significantly higher content of chlorogenic and neochlorogenic acid was found in control berries (110.62 and $99.76 \mathrm{mg}$ per $100 \mathrm{~g}$ fresh weight, respectively). Manganese treatment lowered the amount of chlorogenic acids by $23 \%$, while Alkalin usage caused a $16 \%$ decline. Two unidentified phenolic acids with retention times of $16.4 \mathrm{~min}$ and 35.4 min were determined only in control and Mn treated chokeberries. Especially high levels of the latter acid were observed in Mn treated fruits. The contribution of both unidentified phenolic acids in total phenolic acid content in these berries was $38 \%$.

Significantly higher level of (-)epicatechin was found in control fruits compared to fertilizers treated berries. Polymeric flavan-3-ols of Aronia melanocarpa are mainly composed of (-)epicatechin (Fig. 1). Our results confirm previous data obtained by Oszmiański and Wojdylo (2005) that polymeric procyanidins constitute the major class of phenolics in chokeberries. Manganese treated fruits had significantly lower (-)epicatechin and polymeric procyanidin content. The size of proanthocyanidin molecules can be described by their degree of polymerization (DP) (Wu et al. 2004b). Degree of procyanidins polimerization ranged from $42(\mathrm{Mn}+$ Alkalin) to 59 (control), and the values were lower than determined previously by Oszmiański and Kucharska (1995) 70. Wu et al. (2004b) determined much lower total procyanidin concentrations in chokeberries $(663.7 \mathrm{mg}$ per $100 \mathrm{~g}$ of fresh weight) compared to our results

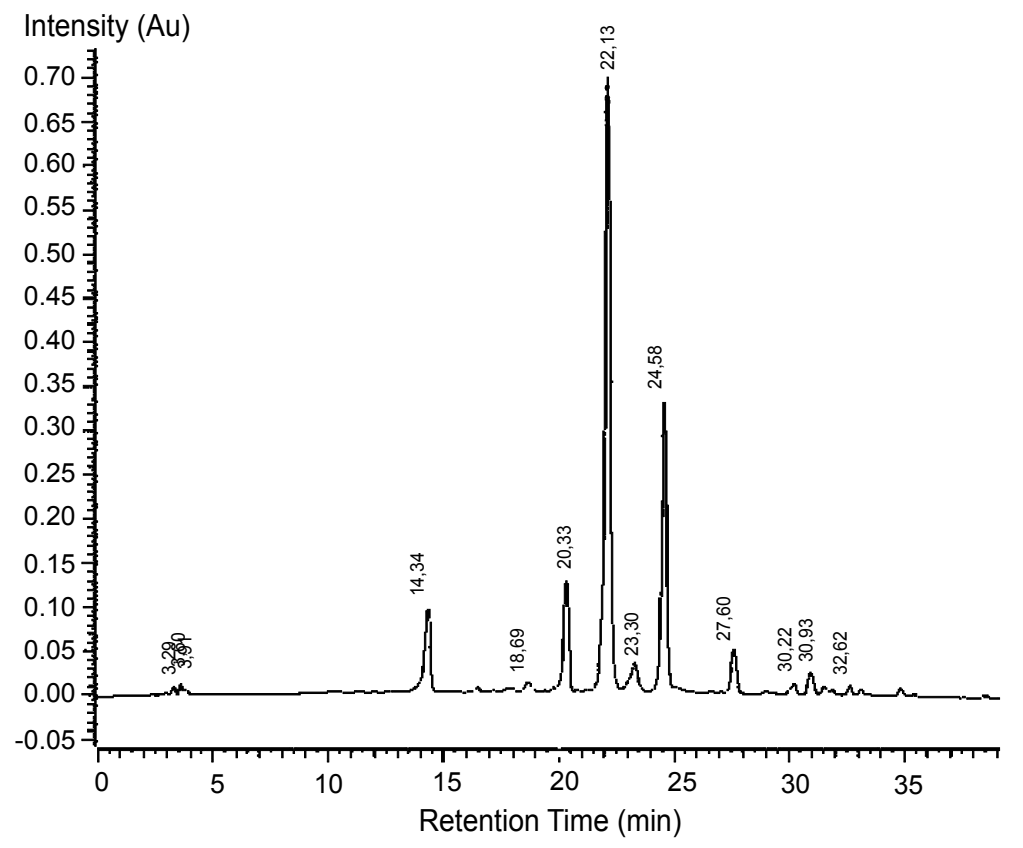

Fig. 1. Chromatogram HPLC $(280 \mathrm{~nm})$ of Aronia melanocarpa (Michx) Elliot fruit extract (control variant). Neochlorogenic acid - $14.34 \mathrm{~min}$, (-)epicatechin - 18.69 $\mathrm{min}$, chlorogenic acid $-20.33 \mathrm{~min}$, cyanidin 3-galactoside -22.13 min, cyanidin 3 -glucoside -23.30 min, cyanidin 3 -arabinoside $24.58 \mathrm{~min}$, cyanidin 3 -xyloside - $27.60 \mathrm{~min}$, eriodictyol 7-glucuronide $-30.93 \mathrm{~min}$, quercetin 3-galactoside $-32.62 \mathrm{~min}$. 


\section{AGRICULTURAL AND FOOD SCIENCE}

Skupień, K. \& Oszmiański, J. Mineral fertilization of chokeberry fruit

(1645.64-1426.66 mg per $100 \mathrm{~g}$ ). The authors found that polymers with degree of polymerization $>10$ constituted predominating subclass of procyanidins (542.6 $\mathrm{mg}$ per $100 \mathrm{~g}$ of fresh weight). According to Ursini et al. (2001), procyanidins are considered to be superior antioxidants compared to their corresponding monomers.

The content of flavonols (quercetin glycosides) ranged from 31.54 (Mn variant) to $40.88 \mathrm{mg}$ per $100 \mathrm{~g}$ (Alkalin), and their participation in total polyphenol content was rather low compared to polymeric procyanidins, cyanidins, and chlorogenic acids. Quercetin 3-galactoside was the main glycoside between quercetin derivatives. Slimestad et al. (2005) determined higher amount of flavonols in chokeberry fruits exceeding $71 \mathrm{mg}$ per $100 \mathrm{~g}$ fresh weight.

In chokeberry fruits, the anthocyanins are the mixture of four cyanidin glysosides: 3-galactoside, 3 -arabinoside, 3-glucoside, and 3-xyloside. Similarly, as observed by Wu et al. (2004b) and Slimestad et al. (2005), cyanidin 3-galactoside turned out to be the dominating glycoside of cyanidin, but its content in our experiment (515.22-473.54 mg per $100 \mathrm{~g}$ ) was much higher than estimated by the above authors (315 mg per $100 \mathrm{~g}$ ). The highest content of cyanidins was observed in Mn treated variant (813.75 mg per $100 \mathrm{~g}$ ), and the lowest in Mn + Alkalin combination (743.80 mg per $100 \mathrm{~g}$ ). Our observations corroborate previous data (Oszmiański and Wojdylo 2005) that anthocyanins constitute second main group of phenolics in aronia fruit.

The presence of flavanone eriodictyol 7glucuronide in chokeberries was first reported by Slimestad et al. (2005). In our experiment, berries of Alkalin treatment showed slightly higher (by 2-4 mg per $100 \mathrm{~g}$ ) eriodictyol content compared to other variants.

\section{Conclusions}

Aronia melanocarpa within Rosaceae family is one of the species with lower cultivation requirements. In addition to natural fertility of the soil (P and $\mathrm{K}$ ) and applied nitrogen fertilization, extra fertilization with Mn, Alkalin (N, K and Si), and Mn + Alkalin caused multi-directional alterations in the content of nutritive and biologically active compounds. Usage of manganese, Alkalin, and manganese + Alkalin significantly lowered total sugar and total polyphenol content in aronia fruit. Berries treated with Alkalin showed negligible sucrose content. No sucrose was found in chokeberries treated with manganese. On the other hand, all the fertilizers increased titratable acidity in chokeberries. Regarding phenolic compounds, all the treatments caused lowering of chlorogenic and neochlorogenic acids, reduced (-)epicatechin content and degree of procyanidins polymerization compared to control fruit. Moreover, Mn treated fruit had significantly higher content of two unidentified phenolic acids with retention times $16.4 \mathrm{~min}$. and $35.4 \mathrm{~min}$ compared to the control; whereas, these acids were not detected in berries treated with Alkalin and $\mathrm{Mn}+$ Alkalin.

Although still preliminary, these results have provided evidence that mineral fertilization may influence the chemical composition of aronia fruits.

Acknowledgements. This project was financially supported by the grant BW/HK/11/2004 of Agricultural University of Szczecin. The authors wish to thank to Józef Grajkowski, $\mathrm{PhD}$, for cultivating chokeberry plants for this study and Jerzy Dmochowski, MSc, for checking the English of the manuscript.

\section{References}

Aherne, S.A. \& O'Brien, N.M. 2002. Dietary flavonols: chemistry, food content, and metabolism. Nutrition 18: 75-81.

Awad, M.A. \& de Jager, A. 2002. Relationship between fruit nutrients and concentrations of flavonoids and chlorogenic acid in 'Elstar' apple skin. Scientia Horticulturae 92: 265-276.

Benvenuti, S., Pellati, F., Melegari, M. \& Bertelli, D. 2004. Polyphenols, anthocyanins, ascorbic acid, and radical scavenging activity of Rubus, Ribes, and Aronia. Journal of Food Science 69, 3: 164-169.

Carbonaro, M., Mattera, M., Nicoli, S., Bergamo, P. \& Cappelloni, M. 2002. Modulation of antioxidant compounds in organic vs. conventional fruit (peach, Prunus persica L., and pear Pyrus communis L.). Journal of Agricultural and Food Chemistry 50: 5458-5462.

Carver, T.L.W., Robbins, M.P., Thomas, B.J., Troth, K., Raistrick, N. \& Zeyan, R.J. 1998. Silicon deprivation enhances localized autoflorescent responses and phenylalanine ammonia-lyase activity in oat attacked by Blumeria graminis. Physiological and Molecular Plant Pathology 52: 245-257.

Chapagain, B.P. \& Wiesman, Z. 2004. Effect of Nutri-VantPeaK foliar spray on plant development, yield, and fruit quality in greenhouse tomatoes. Scientia Horticulturae 102: 177-188. 
Vol. 16 (2007): 46-55

Cheng, G.W. \& Breen, P.J. 1991. Activity of phenylalanine ammonia-lyase (PAL) and concentrations of anthocyanins and phenolics in developing strawberry fruit. Journal of the American Society for Horticultural Science 116, 5: 865-869.

Häkkinen, S.H. \& Törrönen, A.R. 2000. Content of flavonols and selected phenolic acids in strawberries and Vaccinium species: influence of cultivar, cultivation site and technique. Food Research International 33: 517-524.

Jankowski, A., Jankowska, B. \& Niedworok, J. 2000. The influence of Aronia melanocarpa in experimental pancreatitis. Polski Merkuriusz Lekarski 8, 48: 395-398.

Jeppsson, N. 2000. The effects of fertilizer rate on vegetative growth, yield and fruit quality, with special respect to pigments, in black chokeberry (Aronia melanocarpa) cv. 'Viking'. Scientia Horticulturae 83: 127-137.

Justesen, U., Knuthsen, P. \& Leth, T. 1998. Quantitative analysis of flavonols, flavones, and flavanones in fruits, vegetables and beverages by high-performance liquid chromatography with photo-diode array and mass spectrometric detection. Journal of Chromatography A 799: 101-110.

Kähkönen, M.P., Hopia, A.I. \& Heinonen, M. 2001. Berry phenolics and their antioxidant activity. Journal of Agricultural and Food Chemistry 49: 4076-4082.

Kähkönen, M.P., Hopia, A.I., Vuorela, H.J., Rauha, J.-P., Pihlaja, K., Kujala, T.S. \& Heinonen, M. 1999. Antioxidant activity of plant extracts containing phenolic compounds. Journal of Agricultural and Food Chemistry 47: 3954-3962.

Kalemba, D., Góra, J. \& Kurowska, A. 1995. Charakterystyka chemiczna owoców aronii ciemnoowocowej. Przemysł Fermentacyjny i Owocowo-Warzywny 12: 25

Kleparski, J. \& Domino, Z. 1990. Aronia. Państwowe Wydawnictwo Rolnicze i Leśne Warszawa. $100 \mathrm{p}$.

Kong, J.-M., Chia, L.-S., Goh, N.-K., Chia, T.-F. \& Brouillard, R. 2003. Analysis and biological activities of anthocyanins. Phytochemistry 64: 923-933.

Matsumoto, M., Hara, H., Chiji, H. \& Kasai, T. 2004. Gastroprotective effect of red pigments in black chokeberry fruit (Aronia melanocarpa Elliot) on acute gastric hemorrhagic lesions in rats. Journal of Agricultural and Food Chemistry 52: 2226-2229.

Nakajima, J.-I., Tanaka, I., Seo, S., Yamazaki \& Saito, K. 2004. LC/PDA/ESI-MS profiling and radical scavenging activity on anthocyanins in various berries. Journal of Biomedicine and Biotechnology 5: 241-247.

Oghami, K., Ilieva, I., Shiratori, K., Koyama, Y., Jin, X.H., Yoshida, K., Kase, S., Kitiachi, N., Suzuki, Y., Tanaka, T. \& Ohno, S. 2005. Anti-inflamatory effects of aronia extract on rat endotoxin-induced uveitis. Investigative Ophthalmology \& Visual Science 46: 275-281.

Oszmiański, J. \& Kucharska, A. 1995. Taniny aronii. Zeszyty Naukowe Akademii Rolniczej we Wrocławiu. Technologia Żywności 8, 273: 55-65.

Oszmiański, J. \& Wojdylo, A. 2005. Aronia melanocarpa phenolics and their antioxidant activity. European Food Research and Technology 221: 809-813. DOI 10.1007/s00217-0050002-5.

Papadakis, I.E., Protopapadakis, E., Therios, I.N. \& Tsirakoglou, V. 2005. Foliar treatment of Mn deficient 'Washington navel' orange trees with two Mn sources. Scientia Horticulturae 106: 70-75.

Pearson, J.N. \& Rengel, Z. 1997. Genotypic differences in the production and partitioning of carbohydrates between roots and shoots of wheat grown under zinc or manganese deficiency. Annals of Botany 80: 803-808.
Schaffer, S., Schmitt-Schillig, S., Muller, W.E. \& Eckert, G.P. 2005. Antioxidant properties of Mediterranean food plant extracts: geographical differences. Journal of Physiology and Pharmacology 56: 115-124.

Shi, Q., Bao, Z., Zhu, Z., He, Y., Qian, Q. \& Yu, J. 2005. Silicon-mediated alleviation of Mn toxicity in Cucumis sativus in relation to activities of superoxide dismutase and ascorbate peroxidase. Phytochemistry 66: 1551-1559.

Singleton, V.L. \& Rossi, J.A., Jr. 1965. Colorimetry of total phenolics with phosphomolybdic-phosphotungstic acid reagents. American Journal of Enology and Viticulture 16: 144-158.

Slimestad, R., Torskangerpoll, K., Nateland, H.S., Johannessen, T. \& Giske, N.H. 2005. Flavonoids from black chokeberries, Aronia melanocarpa. Journal of Food Composition and Analysis 18: 61-68.

Starck, Z. 2002. Gospodarka mineralna roślin. In: Kopcewicz, J. \& Lewak, S. (ed.). Fizjologia roślin. Państwowe Wydawnictwo Naukowe Warszawa. p. 228-245.

Rossi, M., Giussani, E., Morelli, R., Lo Scalzo, R., Nani, R.C. \& Torreggiani, D. 2003. Effect of fruit blanching on phenolics and radical scavenging activity of highbush blueberry juice. Food Research International 36: 999-1005.

Tomás-Barberán, F.A. \& Espin, J.C. 2001. Phenolic compounds and related enzymes as determinants of quality in fruits and vegetables. Journal of the Science of Food and Agriculture 81: 853-876.

Ursini, F., Rapuzzi, I., Toniolo, R. \& Tubaro, F. 2001. Characterization of antioxidant effect of procyanidin. Methods in Enzymology 335: 338-350.

Valcheva-Kuzmanova, S., Borisova, P., Galunska, B., Krasnaliev, I. \& Belcheva, A. 2004. Hepatoprotective effect of the natural fruit juice from Aronia melanocarpa on carbon tetrachloride-induced acute liver damage in rats. Experimental and Toxicologic Pathology 56, 3: 195-201.

Valcheva-Kuzmanova, S., Marazova, K., Krasnaliev, I., Galunska, B., Borisova, P. \& Belcheva, A. 2005. Effect of Aronia melanocarpa fruit juice on indomethacin-induced gastric mucosal damage and oxidative stress in rats. Experimental and Toxicologic Pathology 56, 6: 385-92.

Wu, X., Beecher, G., Holden, J., Haytowitz, D., Gebhardt, S.E. \& Prior, R.L. 2004a. Lipophilic and hydrophilic antioxidant capacities of common foods in the United States. Journal of Agricultural and Food Chemistry 52: 4026-4037.

Wu, X., Liwei, G., Prior, R.L. \& McKay, S. 2004b. Characterization of anthocyanins and proanthocyanidins in some cultivars of Ribes, Aronia, and Sambucus and their antioxidant capacity. Journal of Agricultural and Food Chemistry 52: 7846-7856.

Yen, G.-C. \& Chen, H.-Y. 1995. Antioxidant activity of various tea extracts in relation to their antimutagenicity. Journal of Agricultural and Food Chemistry 43: 27-32.

Yilmaz, Y. \& Toledo, R.T. 2004. Major flavonoids in grape seeds and Skins: antioxidant capacity of catechin, epicatechin and gallic acid. Journal of Agricultural and Food Chemistry 52: 255-260.

Zheng, W. \& Wang, S.Y. 2003. Oxygen radical absorbing capacity of phenolics in blueberries, cranberries, chokeberries and lingonberries. Journal of Agricultural and Food Chemistry 51: 502-509. 